\title{
A novel therapeutic option in Cogan diseases? TNF- $\alpha$ blockers
}

\author{
M. Fricker • A. Baumann • F. Wermelinger • \\ P. M. Villiger • A. Helbling
}

Received: 20 May 2006 / Accepted: 28 September 2006 / Published online: 11 November 2006

(C) Springer-Verlag 2006

\begin{abstract}
Cogan's syndrome is characterized by noninfectious, interstitial keratitis combined with a vestibulo-auditory deficit. Despite therapy with corticosteroids in combination with immunosuppressive agents, relapses occurred in two subjects and the clinical course suggested a progression of the disease. Treatment with anti-TNF- $\alpha$ was started leading to a rapid and sustained clinical remission for over 2 respectively 3 years.
\end{abstract}

Keywords Cogan's syndrome $\cdot$ Disease relapse · TNF- $\alpha$ blocker $\cdot$ Infliximab $\cdot$ Remisson

\section{Introduction}

Characteristic manifestations of Cogan's syndrome described for the first time in 1945 [1] are a non-infectious, interstitial keratitis combined with a vestibuloauditory deficit. Associations with aortitis and systemic vasculitis have been described. The Cogan syndrome commonly occurs in adults in the third decade of life [1]. In approximately half of the patients' eye involvement, and in one-third inner ear disorders are the first symptoms $[2,3]$. Besides interstitial keratitis

M. Fricker $\cdot$ F. Wermelinger $\cdot$ P. M. Villiger $\cdot$ A. Helbling $(\bowtie)$ Division of Allergology, Policlinics of Allergy

and Immunology, Department of Rheumatology and Clinical Immunology/Allergology, University Hospital (Inselspital), 3010 Bern, Switzerland

e-mail: arthur.helbling@insel.ch

\section{A. Baumann}

Department of ENT and Head and Neck Surgery,

University Hospital (Inselspital), 3010 Bern, Switzerland causing eye redness, blurred vision, photophobia and pain, other parts of the eye may also be involved leading to conjunctivitis, iridocyclitis, scleritis or retinitis. Ear involvement often goes along with hearing loss, vertigo or ataxia and can cause nausea or vomiting. To prevent persistent deafness and other sequels due to this inflammatory process, commonly corticosteroids and other immunosuppressive agents are used for treatment [4]. In this article we describe the cases and further courses in two patients with Cogan's syndrome, we reported before [5]. Because of the relapse of the illness, as often seen in Cogan's patients, therapy was changed to TNF- $\alpha$ inhibitor and led to a remission.

\section{Case reports}

Case 1 (F.P. 1967)

In November 2000 diagnosis of Cogan's syndrome was made in a 33-year-old man based on a bilateral progressive hearing loss, tinnitus and ataxia, as well as a bilateral interstitial keratitis following a viral infection of the upper airways. A therapy with topical ocular and systemic corticosteroids ( $1 \mathrm{mg} / \mathrm{kg}$ body weight) resulted in a rapid improvement of the eye manifestations. However, hearing loss and ataxia became worse. Because of a severe maculopapular exanthema, therapy with azathioprine $150 \mathrm{mg}$ daily was stopped after 3 weeks and cyclophosphamide $1 \mathrm{~g}$ as pulse-therapy was given intravenously from January till June 2001 . While the hearing on the right side did not recover, the left side improved partially. Although the patient remained on a maintenance therapy with prednisone 
$20 \mathrm{mg}$ per day, a relapse with an acute hearing loss of the left side occurred in July 2002. Intravenous cyclophosphamide therapy was immediately restarted, and prednisone dose was increased to $100 \mathrm{mg}$ per day. However, due to insufficient therapeutic effect, an infusion of infliximab $(300 \mathrm{mg})$ was given in April 2003. Within a few days following the first infusion, an improvement of the hearing loss to the pre-relapse state was achieved. Infliximab $300 \mathrm{mg}$ was given in monthly intervals, oral prednisone was reduced gradually and completely stopped in February 2004. Because the hearing conditions remained stable, infliximab therapy has been extended to a 10 week and finally a 3 month interval. Hearing and vestibular conditions remained stable (Fig. 1) and showed a favourable course with the patient in an otherwise good health doing regularly sports like playing squash, running or biking. This condition is now remaining pleasant for 1 year without any therapy.

\section{Case 2 (X.D. 1951)}

Within a few weeks, isolated bilateral hearing loss developed in this 49-year-old man. Nine months later, in June 2000, recurrent fever, arthralgias and severe bilateral nodular scleritis occurred. Oto-neurological examination showed a two-sided sensorineural hearing loss in the high frequency tones, and a unilateral peripheral vestibular deficit with a caloric hyporeflexia on the left side. In November 2000 due to persisting subfebrility, echocardiography revealed a mild aortic insufficiency. The diagnosis of Cogan's syndrome was finally made, and therapy with oral prednisone was started at a daily dose of $2 \mathrm{mg} / \mathrm{kg}$. While hearing loss improved, fever persisted and the ocular manifestations progressively worsened. Oral cyclophosphamide ( $2 \mathrm{mg} / \mathrm{kg}$ body weight) was added 1 month later.

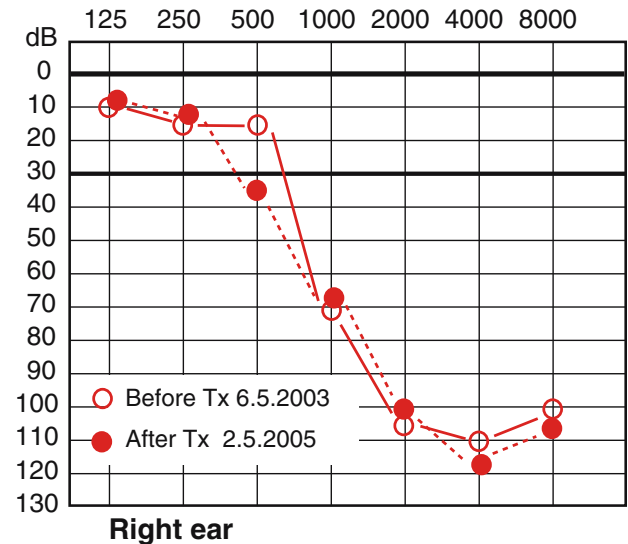

Episcleritis and scleritis then completely resolved within 6 weeks, subsequently prednisone was reduced to $5 \mathrm{mg}$ per day. Although treatment with cyclophosphamide was continued, scleritis recurred in January 2002. Infusion with infliximab $300 \mathrm{mg}$ was started in January 2002, and repeated every 6 weeks. Due to persistent arthralgias leflunomide $20 \mathrm{mg}$ per day was added. Thereafter ocular manifestations completely disappeared and did not recur. Oral prednisone was continuously tapered and discontinued in May 2003. Infliximab dose was increased to $400 \mathrm{mg}$ and the interval was prolonged to 8 weeks. Hearing function remains stable, especially a transient subjective and objective improvement can be seen 1 week after the infusion of infliximab (Fig. 2).

\section{Discussion}

Cogan's syndrome is an inflammatory disease of unknown origin. Study results indicate an autoimmune pathogenesis. A decade ago, antibodies against corneal and inner ear tissue have been detected [6-8]. More recently, antibodies against a peptide-antigen have been found in sera from patients with Cogan's syndrome. These peptide-antigens share sequence homology with CD148 and connexin 26 that are expressed in the inner ear [6]. In addition, histopathological examination of corneal tissue and cochlea from patients with Cogan's disease also showed lymphocytic and plasma cell infiltration suggesting a cell-mediated reaction $[6,9]$.

Because hearing loss usually is bilateral and progressive and eventually results in deafness (up to 60\%) [9], early treatment is essential. Several publications report that treatment with corticosteroids as mono-therapy may fail, but combination therapy with immunosuppressants such as cyclophosphamide, cyclosporine or

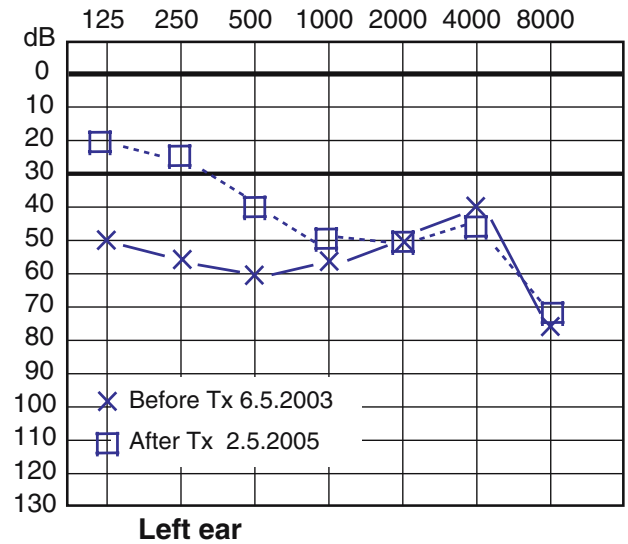

Fig. 1 Course of hearing function in pure tone audiogram of case 1 

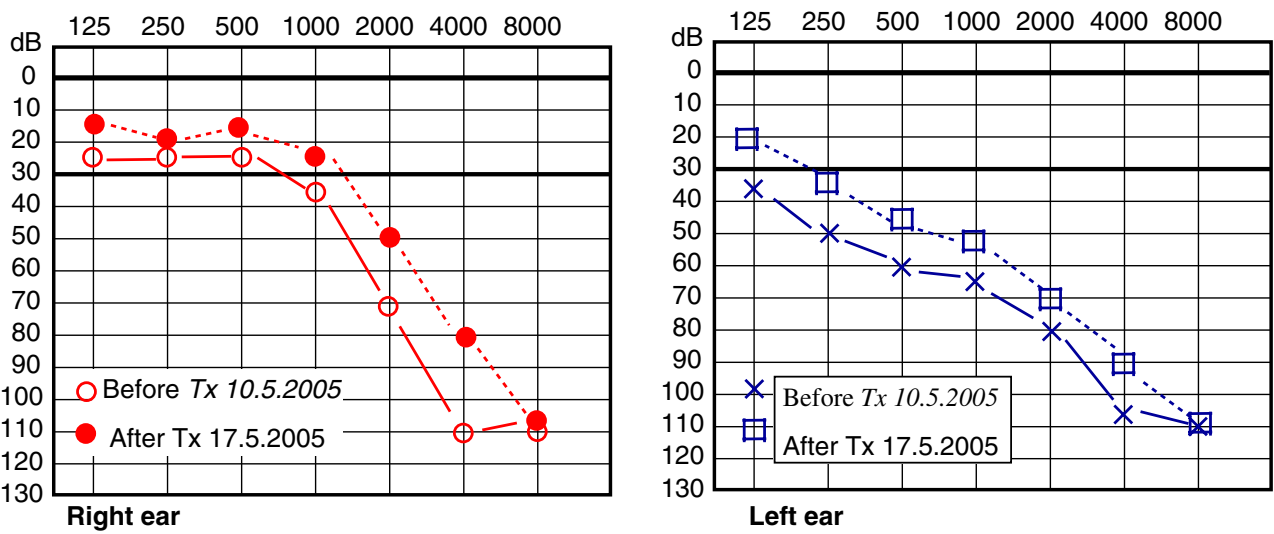

Fig. 2 pure tone audiogram in case 2 immediately before and 7 days after infusion of infliximab

methotrexate may lead to favourable outcomes $[4,10$ 13]. However, even in patients with early immunosuppressive treatment, hearing improvements is often incomplete [5]. This may be due to insufficient concentrations of drugs at the affected sites.

As both of our patients did not respond satisfactorily to a combined therapy of oral prednisone and cyclophosphamide, or even relapsed under established treatment, infliximab, a chimeric monoclonal antibody against TNF- $\alpha$ was given. As shown earlier, this antiinflammatory and immunosuppressive strategy may show rapid and sustained effects in various inflammatory syndromes $[13,14]$.

Therapy with infliximab was well tolerated in both patients. Although in one patient the interval was extended up to 3 months and immunosuppressive therapy was now stopped for 1 year, no relapse of the Cogan syndrome was observed. In conclusion treatment with the TNF- $\alpha$ inhibitor infliximab appears to be effective in inducing and maintaining remission in patients with therapy-resistant Cogan's syndrome.

\section{References}

1. Cogan DG (1945) Syndrome of nonsyphilitic interstitial keratitis and vestibuloauditory symptoms. Arch Ophthalmol 33:144

2. Haynes BF, Kaiser-Kupfer MI, Mason P, Fauci AS (1980) Cogan syndrome: studies in thirteen patients, long-term follow up, a review of the literature. Medicine (Baltimore) 59:426-439

3. Vollertsen RS, McDonald TJ, Younge BR, Banks BM, Stanson AW, Ilstrup DM (1986) Cogan's syndrome: 18 cases and a review of the literature. Mayo Clin Proc 61:344-361
4. Allen NB, Cox CC, Cobo M, Kisslo J, Jacobs MR, Mc Callum RM, Haynes BF (1990) Use of immunosuppressive agents in the treatment of the severe ocular and vascular manifestations of Cogan's syndrome. Am J Med 88:296-301

5. Baumann A, Helbling A, Oertle S, Häusler R, Vibert D (2005) Cogan's syndrome: clinical evolution of deafness and vertigo in three patients. Otology 262:45-49

6. Lundardi C, Bason C, Leandri M, Navone R, Lestani M, Millo E et al (2002) Autoantibodies to inner ear and endothelial antigens in Cogan's syndrome. Lancet 360:915-921

7. Arnold W, Gebbers JO (1984) Serum-Antikörper gegen Kornea und Innenohrgewebe beim Cogan-Syndrom. Laryngol Rhinol Otol 63:428-432

8. Helmchen C, Arbusow V, Jäger L, Strupp M, Stöcker W, Schulz P (1999) Cogan's syndrome: clinical significance of antibodies against the inner ear and cornea. Acta Otolaryngol 119:528-537

9. St. Clair EW, McCallum RM (1999) Cogan's syndrome. Curr Opin Rheumatolog 11:47-52

10. Matteson EL, Tirzaman O, Facer GW, Fabry DA, Kaperbauer J, Beatty CW, McDonald TJ (2000) Use of methotrexate for autoimmune hearing loss. Ann Otol Rhinol Laryngol 109:710-714

11. Riente L, Taglione E, Berrettini S (1996) Efficacy of methotrexate in Cogan's syndrome. J Rheumatol 23:1830-1831

12. Kasapcopur OE, Ashraf M, Caliskan S, Arisoy N (2000) Cogan's syndrome: a rare vasculitis in childhood. J Rheumatol 27:1824-1825

13. Lipsky PE et al (2000) Infliximab and methotrexate in the treatment of rheumatoid arthritis. Anti-tumour necrosis factor trial in rheumatoid arthritis with Concomitant Therapy Study Group. N Engl J Med 343:1594-1602

14. Aeberli D, Oertle S, Mauron H, Reichenbach S, Jordi B, Villiger PM (2002) Inhibition of the TNF-pathway use of infliximab an etanercept as remission-inducing agents in cases of therapy resistant chronic inflammatory disorders. Swiss Med Wkly 132(29-30):414-422 